\title{
Multi objective optimization of microalgae flat plate photobioreactor design
}

\author{
Arif Rahman ${ }^{1}$, Sanjaya BS Nasution ${ }^{1}$, Sri RH Siregar ${ }^{1}$, and Nasruddin ${ }^{1 *}$ \\ ${ }^{1}$ Department of Mechanical Engineering, Faculty of Engineering, Universitas Indonesia, Kampus UI Depok, Depok 16424, \\ West Java, Indonesia
}

\begin{abstract}
Indonesia as a maritime country has high potential in developing microalgae. Microalgae in Indonesia have a high oil component of around $20-30 \%$, for example Nitzschia palea $(23 \%)$, Chlorella vulgaris $(27 \%)$, and Euglena gracilis $(20 \%)$. In addition to biofuel production, the microalgae species chlorella vulgaris can also be used as part of wastewater treatment. This paper aims to optimize the photo-bioreactor design for microalgae with multi-objective functions including exergy and economics. One method used is the Multi-Objective Multi-Verse Optimizer (MOMVO). MOMVO optimization is related to several objective functions with specified constrain. Objective functions and constraints will be resolved in the form of algorithmic functions. From the optimization results using the Multi-Objective Multi-Verse Optimizer (MOMVO), it can be concluded that the optimum exergy value is at $1292.5 \mathrm{~cd}$ and the pressure is $3.34 \mathrm{kPa}$ with an exergy destruction value of $23,424.96 \mathrm{~kW}$ and a total cost of $\$ 42,744.85$. While the optimum economic value is at $1292.51 \mathrm{~cd}$ and the pressure is $3.34 \mathrm{kPa}$ with an exergy value of destruction of $23,726.82 \mathrm{~kW}$ and a total cost of $\$ 42,837.36$.
\end{abstract}

\section{Introduction}

Indonesia as a maritime country has high potential to develop microalgae. Hadiyanto et al analyzed the potential of microalgae as a biofuel in Indonesia. Microalgae in Indonesia have a high oil component of around $20-30 \%$, for example Nitzschia palea $(23 \%)$, Chlorella vulgaris (27\%), and Euglena gracilis (20\%) [1]. In addition to biofuel production, microalgae species chlorella vulgaris can also be used for wastewater treatment. Dianursanti et al investigated Chlorella vulgaris cultivation using industrial tofu wastewater [2]. Chlorella vulgaris produced can be used for wastewater treatment and lipid production for biofuels.

Microalgae biomass is needed in large quantities to produce biofuels. One way to produce biomass is Microalgae cultivation using the concept of photobioreactor which has more advantages than open ponds or natural cultivation. The advantage of photo-bioreactor is the more even distribution of light, less contaminants, less evaporation and lower production costs [3].

Carvalho et al. reviewed several types of closed bioreactors to support microalgae production [4]. Based on its shape, the photo-bioreactor can be classified as a tubular reactor, flat plate reactor, and fermenter type reactor. The three types of reactors have the same basic principles. However, there are differences such as the level of efficiency in harvesting, the spread of light, the level of control, the area needed, and probability. Each type of reactor can optimally grow certain microalgae species. This paper aims to optimize the photo-bioreactor design for microalgae with multi-objective functions such as exergy and economics. This paper uses flat plate reactors with light intensity and pressure drop as optimization variables.

\section{Method}

\subsection{Flat Plate Reactor}

Photo-bioreactor design is one of the main factors that must be considered in the process of microalgae growth [4]. Besides that there are also internal and external factors involved in the photo-bioreactor. This is related to the intensity of the light and the pressure gauge that the photo-bioreactor will receive. Therefore, it is designed by considering the light intensity and pressure gauge that is in accordance with the characteristics of microalgae. One of the most commonly used reactor designs is a flat plate reactor. In general, the main advantages of flat plate reactors are high productivity and even distribution of light [5]. Flat plate reactor in this research uses tubular lamp (TL) as a light source and pressure gauge from the compressor to distribute fluid and nutrients in the photobioreactor. Figure 1 is a flat plat photo-bioreactor.

\subsection{Optimization of System}

Variations in the light intensity of the lamp and the pressure gauge of the compressor will have a different effect on the photo-bioreactor's ability to produce microalgae. The use of these two components is very dependent on the power needed. The higher the light

\footnotetext{
* Corresponding author: nasruddin@eng.ui.ac.id
} 
intensity and the pressure gauge required, the higher the power required by the lamp and compressor. Pump and lamp power are related to energy and exergy working in the photo-bioreactor system. In this paper an exergy and economic optimization of the photo-bioreactor system was carried out. Variations in the light intensity of the lamp and the pressure gauge of the compressor are optimized through an objective function to minimize costs. These costs include operational costs and capital costs.

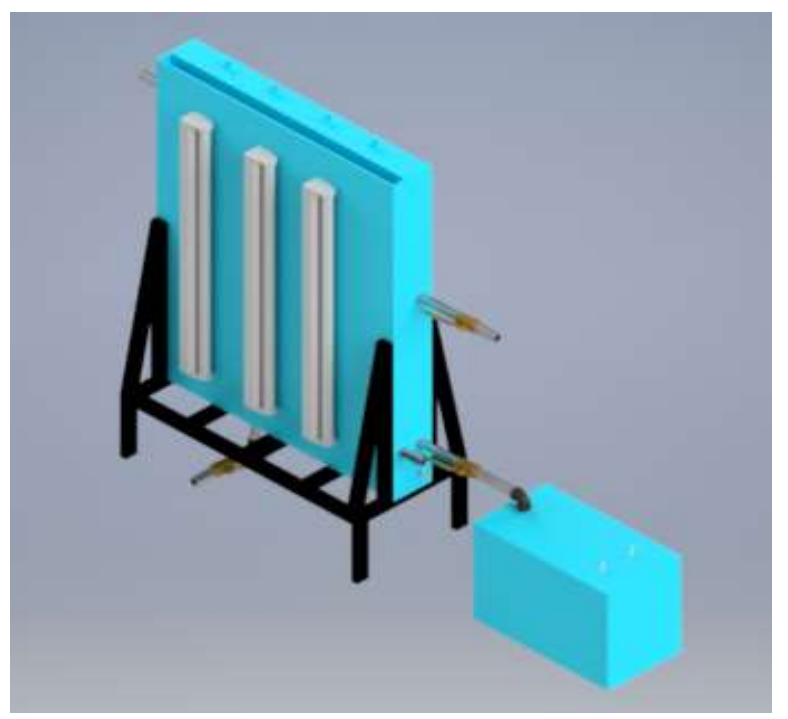

Fig. 1. Flat plate photo-bioreactor

\subsection{MOMVO}

The development of computer technology causes the optimization system engineering methodology to develop. Previous problem solving is difficult because many complex equations can now be solved more quickly and accurately. One method used is the Multi-Objective Multi-Verse Optimizer (MOMVO). MOMVO is the latest development of the Multi-Verse Optimizer (MVO) method [6].

MOMVO optimization is related to several objective functions with specified constrains. Objective functions and constraints will be resolved in the form of algorithmic functions. In this paper, there are two objective functions such as an exergy and economy, while constraints are intensity and pressure gauge.

\section{Governing Equation}

\subsection{Exergy}

Exergy is the maximum amount of work carried out by a system obtained from equilibrium results with the environment. [7]. Table 1 below is the standard exergy value of each chemical from culture media for microalgae growth.

Exergy of Culture Media

$$
\dot{E} x_{C M}=\sum n_{i} \dot{E}_{i}
$$

Table 1. Chemical standard exergy of culture media for microalgae growth.

\begin{tabular}{|c|c|c|}
\hline Name & $\begin{array}{c}\text { Chemical } \\
\text { formula }\end{array}$ & $\begin{array}{c}\text { Standard } \\
\text { chemical } \\
\text { exergy } \\
\text { (kJ/mol) }\end{array}$ \\
\hline $\begin{array}{c}\text { Magnesium sulphate } \\
\text { heptahydrate }\end{array}$ & $\mathrm{MgSO}_{4} .7 \mathrm{H}_{2} \mathrm{O}$ & 87 \\
\hline $\begin{array}{c}\text { Calcium chloride } \\
\text { dehydrate }\end{array}$ & $\mathrm{CaCl}_{2} .2 \mathrm{H}_{2} \mathrm{O}$ & 89.7 \\
\hline $\begin{array}{c}\text { Potassium } \\
\text { dihydrogen } \\
\text { phosphate }\end{array}$ & $\mathrm{KH}_{2} \mathrm{PO}_{4}$ & 50.07 \\
\hline $\begin{array}{c}\text { Dipotassium } \\
\text { hydrogen phosphate }\end{array}$ & $\mathrm{K}_{2} \mathrm{HPO}_{4}$ & 78.92 \\
\hline $\begin{array}{c}\text { Zinc sulphate } \\
\text { heptahydrate }\end{array}$ & $\mathrm{ZnSO}_{4} .7 \mathrm{H}_{2} \mathrm{O}$ & 88.6 \\
\hline Boric acid & $\mathrm{H}_{3} \mathrm{BO}_{3}$ & 21.97 \\
\hline $\begin{array}{c}\text { Copper sulphate } \\
\text { pentahydrate }\end{array}$ & $\mathrm{CUSO}_{4} .5 \mathrm{H}_{2} \mathrm{O}$ & 91.39 \\
\hline Ammonium sulphate & $\left(\mathrm{NH}_{4}\right) 2 \mathrm{SO} 4$ & 660.6 \\
\hline Sodium hydroxide & $\mathrm{NaOH}$ & 74.9 \\
\hline Hydrogen chloride & $\mathrm{HCL}$ & 84.5 \\
\hline
\end{tabular}

Exergy of Air Flow Rate

$$
\dot{E} x_{A F}=\mathrm{R} T_{0} \ln \left(\frac{P_{0}+\Delta P}{P_{0}}\right)
$$

Exergy of Cooling Water

$$
\dot{E} x_{C W}=\dot{m}_{C W} C_{C W}\left[T_{C W}-T_{0}-T_{0} \ln \left(\frac{T_{C W}}{T_{0}}\right)\right]
$$

Exergy of Delivered Light

$$
\dot{E} x_{D L}=(1-C r) \propto \mathrm{AI}_{T L}
$$

Exergy Destruction

$$
\dot{E}_{D}=\dot{E}_{F}-\dot{E_{P}}
$$

\subsection{Economic}

Photo-bioreactor requires two main components that function to produce microalgae biomass. Previous research has shown that light intensity affects microalgae growth [5]. In addition, the compressor that serves to distribute fluid and nutrients also affects the growth of microalgae. In this study, economic optimization is carried out to determine the value of capital costs and operational costs which are the power functions of both components, namely lamps and compressors.

Capital costs and operating costs are total component costs. Capital costs are calculated based on the cost equation as a power function. The capital cost equation of the two components is [8]:

Compressor:

$$
C_{c}=10167.5 \times W_{c}^{0.46}
$$


Lamp

The calculation of capital cost of the lamp is calculated by determining the cost function between the price and the power lamp contained in the market. The function is:

$$
C_{l}=37,500 * W_{l}+108,333
$$

Economic optimization conducted in this study is to calculate the total cost per year (total annual cost). The total cost overall equation:

Total Cost $=\left(C_{c}+C_{l}\right) * C R F+C_{e l} H *\left(W_{c}+W_{l}\right)$

The Capital Recovery Factor (CRF) is a parameter used to determine annual capital costs. The CRF value is obtained from the equation below [9] :

$$
\mathrm{CRF}=\frac{i *(1+i)^{n}}{(1+i)^{n-1}}
$$

\section{Variable of Optimization}

\subsection{Intensity}

Light intensity is one of the important parameters in the growth and productivity of microalgae [10]. In this paper, light intensity varied from 1000-1500 cd.

\subsection{Compressor Pressure}

The design of the compressor depends on the mass of the liquid and the pressure drop. Both variables affect the power consumption to drain the liquid. Variations of these variables are related to changes in compressor power. In this study, the mass of fluid has been determined and the pressure drop has changed. Variation in pressure drop is 1 $\mathrm{kPa}-5 \mathrm{kPa}$. The equation below is the compressor power associated with fluid mass and pressure drop [11].

$$
W_{c}=\mathrm{m} * \Delta \mathrm{P}
$$

\section{Result and Discussion}

\subsection{Exergy and economic}

From exergy and exergoeconomic analysis, it can be seen that components such as photo-bioreactors, compressors, lamps and chemicals are components that greatly contribute to the value of exergy destruction and total costs. Therefore, the optimization procedure is carried out, so that the system can work efficiently both in terms of energy and economy by finding the optimal value of several operating parameters.

Exergy destruction and total cost are objective functions to determine the optimal conditions of the photo-bioreactor system. In the Multi-Objective MultiVerse Optimizer (MOMVO) procedure, exergy destruction and exergoeconomic are expected to have a minimum value by providing constrains. In this paper, the intensity of the lamp and pressure gauge were chosen as decision variables, which then searched the optimum value to produce minimum exergy destruction and total costs. Based on the optimization results performed using MOMVO, the optimum value is shown in Figure 2.

From the optimum value obtained, it is displayed in the form of parretto graph and the TOPSIS method is needed to determine the most optimum point. TOPSIS is the method used to select the optimum point from a series of optimum values illustrated in the Parretto Front graph. This method selects the optimum value by determining the non-ideal point, the point that has a value that is far from the optimum point and the ideal point, which has the most optimum value.

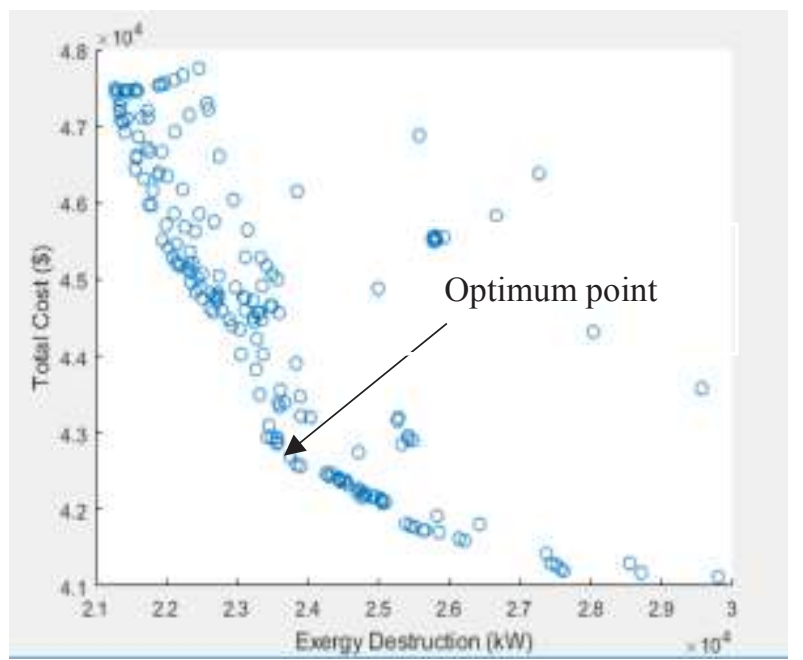

Fig. 2. Optimum Value of MOMVO Optimization results

Furthermore, the optimum value is chosen by taking the point that is the furthest away from the point that is not ideal and closest to the ideal point. The selected

\begin{tabular}{|c|c|c|c|}
\hline No & Parameter & $\begin{array}{c}\text { Optimum } \\
\text { Exergy }\end{array}$ & $\begin{array}{l}\text { Optimum } \\
\text { Economic }\end{array}$ \\
\hline \multicolumn{4}{|c|}{ Constrain } \\
\hline 1 & Intensity (cd) & 1292.5 & 1292.51 \\
\hline 2 & $\begin{array}{l}\text { Compressor } \\
\text { Pressure }\end{array}$ & 3.34 & 3.34 \\
\hline \multicolumn{4}{|c|}{$\begin{array}{l}\text { Objective } \\
\text { Function }\end{array}$} \\
\hline 1 & $\begin{array}{ll}\text { Total Exergy } \\
\text { Destruction }(\mathrm{kW})\end{array}$ & $23,424.96$ & $23,726.82$ \\
\hline 2 & Total Cost $(\$)$ & $42,744.85$ & $42,837.36$ \\
\hline
\end{tabular}
optimum point is presented in Table 2 .

Table 2. Optimum point of optimization with MOMVO

Based on Table 2, the optimization results show that the optimum exergy and economic values occur in each light intensity $1292.5 \mathrm{~cd}$ and $1292.51 \mathrm{~cd}$, the pressure drop is $3.34 \mathrm{kPa}$ with a total exergy destruction of 23.424 .96 $\mathrm{kW}$ and $23.726 .82 \mathrm{~kW}$ and the total cost of $\$ 2.744 .85$ and $\$ 42.837 .36$. The optimum value shows that the optimization results obtained by the system work efficiently and have the minimum value of exergy destruction and economy. This is because the light 
intensity of $1292.5 \mathrm{~cd}$ and pressure drop of $3.34 \mathrm{kPa}$ can be well received by microalgae so that it can grow quickly.

\section{Conclusions}

From the optimization result using Multi-Objective Multi-Verse Optimizer (MOMVO), we can conclude that the optimum exergy value is at the intensity $1292.5 \mathrm{~cd}$ and compressor pressure $3.34 \mathrm{kPa}$ with exergy destruction value $23,424.96 \mathrm{~kW}$ and total cost USD 42,744.85. While the optimum economic value is at the intensity of 1292.51 cd and compressor pressure $3.34 \mathrm{kPa}$ with exergy destruction value $23,726.82 \mathrm{~kW}$ and total cost USD 42,837.36.

This research was funded by Hibah Publikasi Internasional Terindeks untuk Tugas Akhir Mahasiswa (Hibah PITTA) Universitas Indonesia Tahun Anggaran 2018 to Nasruddin, grand. no. 2498/UN2.R3.1/ HKP.05.00 / 2018.

\section{References}

1. Andri, C.K., Potency of microalgae as biodiesel source in Indonesia. International Journal of Renewable Energy Development. 1(1): p. 23-27 (2012)

2. Rizkytata, B.T., M.T. Gumelar, and T.H. Abdullah, Industrial tofu wastewater as a cultivation medium of microalgae Chlorella vulgaris. Energy Procedia, 47: p. 56-61 (2014)

3. Gouveia, L. and A.C. Oliveira, Microalgae as a raw material for biofuels production. Journal of industrial microbiology \& biotechnology, 36(2): p. 269-274 (2009).

4. Carvalho, A.P., L.A. Meireles, and F.X. Malcata, Microalgal reactors: a review of enclosed system designs and performances. Biotechnology progress, 22(6): p. 1490-1506 (2006).

5. Richmond, A. and Z. Cheng-Wu, Optimization of a flat plate glass reactor for mass production of Nannochloropsis sp. outdoors. Journal of Biotechnology, 85(3): p. 259-269 (2001).

6. Mirjalili, S., et al., Optimization of problems with multiple objectives using the multi-verse optimization algorithm. Knowledge-Based Systems, 134: p. 50-71 (2017).

7. Aghbashlo, M., et al., Exergy analysis for decision making on operational condition of a continuous photobioreactor for hydrogen production via WGS reaction. International journal of hydrogen energy, 41(4): p. 2354-2366 (2016).

8. Smith, R., Chemical process: design and integration, John Wiley \& Sons (2005).

9. Bejan, A., G. Tsatsaronis, and M. Moran, Thermal design and optimization, John Wiley \& Sons (1996).

10. Kwon, J.-H., M. Rögner, and S. Rexroth, Direct approach for bioprocess optimization in a continuous flat-bed photobioreactor system. Journal of biotechnology, 162(1): p. 156-162 (2012).
11. Harinaldi, B., Sistem Fluida : Prinsip Dasar dan Penerapan Mesin Fluida, Sistem Hidrolik, dan Sistem Pneumatik, Jakarta: Erlangga (2015).

\section{Nomenclatur}

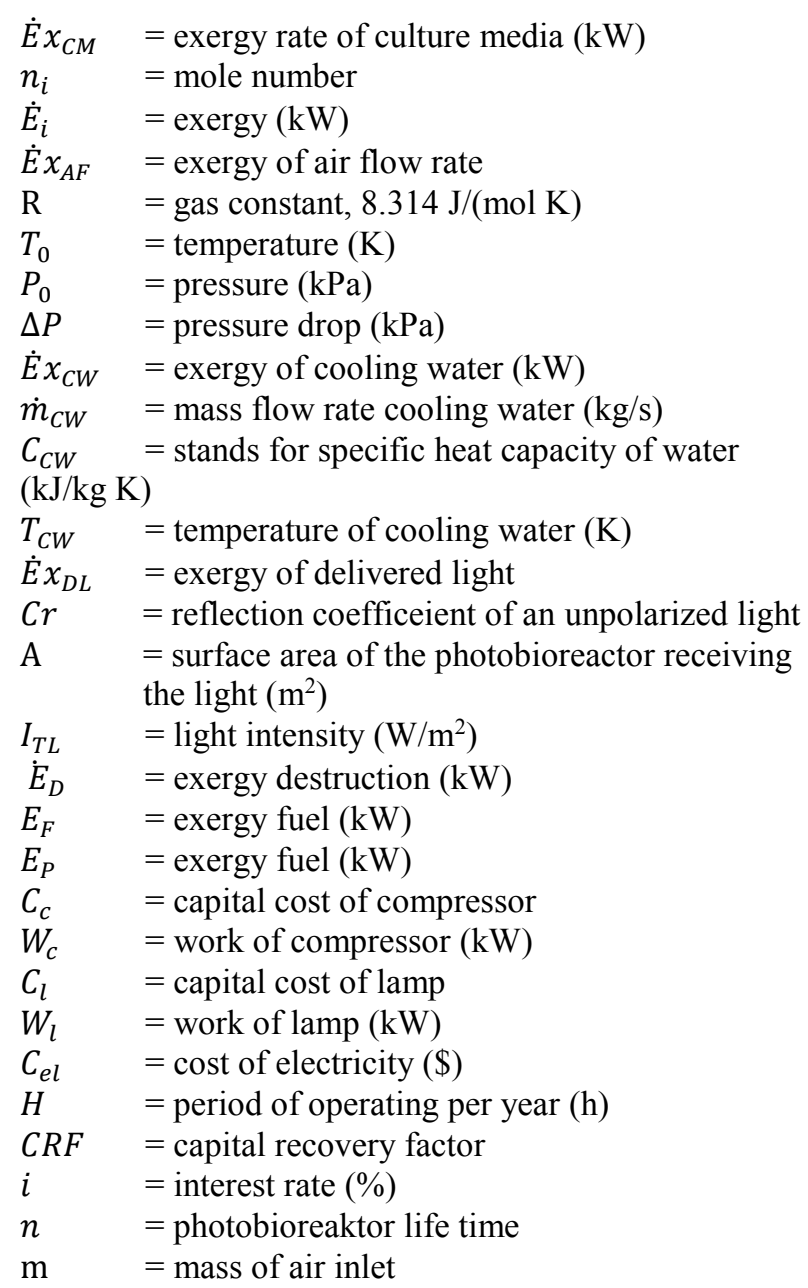

